\title{
Development of Educational Toy: Jumping Alphabet
}

\author{
Pravissi Shanti \\ Fakultas Pendidikan Psikologi, Universitas Negeri Malang \\ Corresponding e-mail: shantie.hakim@gmail.com
}

\begin{abstract}
Today, children begin to learn to read at an early age with the assumption that the earlier a child learns to read, they will develop better. On the other hand, many people thought that learning to read before school age, which is 7 years old in Indonesia, it will hamper the development of the child. Regardless of polemics about when a child should be taught to read, in Indonesia the teaching of reading has begun to be given in kindergartens. Kindergarten (TK) is the level of non-formal education that teaches children at early age about the wide variety of basic skills, including letters and numbers, with the assumption that the acquisition of letters and figures are basic skills that must be understood by younger children before they enter the next education level. The development of this toys aims to help teachers and parents as a media for letters and words recognition in early childhood, as a basic for learning to read. Based on observations conducted by researchers at several kindergartens in the city of Malang, letters and words recognition given to their students using the media such as flash cards. This method is quite effective and fun with a variety of images on a flash card that can attract children to learn to read. However, learning by using flash card is not stimulating the motor development of children, especially gross motor skills. Gross motor development is actually an important aspect of development in early childhood. Thus, researchers are trying to design an educational toy that combines the method of flash cards with physical activities that can be used to stimulate gross motor skills of young children. The toy is called Jumping Alphabet, consisting of a pictorial carpet pads consist of 26 letters written in rectangle areas and an assortment of flash cards containing pictures and words. Kids are asked to spell out the letters on the flash card by jumping into the rectangle area containing the corresponding letter. It is expected therefore, in addition to the ability of recognition of letters and words that children develop, it can also stimulate the development of gross motor abilities
\end{abstract}

Keywords: reading, early childhood, educational toy, letters

\section{INTRODUCTION}

Early childhood is a phase in human life that can be considered as the most important one. At this time, children learn a variety of things that will be very useful in their lives in the next stage of development. One of the skills that are taught to the children at this moment is the ability to read. It is a process that develops through stages of the child's development, especially cognitively. However, today most people assume, that the earlier children are taught to read, the child's reading ability will improve. Some opinions say, they are not. When children are not ready, but they are forced to read, the result would not be optimal, but it will hamper the development of children's potential. Early childhood is a time where children should develop motor skills, which is fine motor skills and also gross motor skills that also have a significant impact on a child's development in the next stage of life. Motor development in early childhood may be obtained through opportunities to move, learning experiences concretely, and also through sensory motor activities that involves the use of large and small muscles.

In Indonesia, the teaching of reading in children starts when they are in kindergarten. Kindergarten (TK) is the level of non-formal education that teaches children at an early age about the wide variety of basic skills, including letters and numbers, with the assumption that the acquisition of letters and figures are a basic skills that must be understood by younger children before they enter the next education level.

Based on observations conducted by researchers at several kindergartens in the city of 
Malang, letters and words recognition given to their students using the media such as flash cards. This method is quite effective and fun with a variety of images on a flash card that can attract children to learn to read. However, learning by using flash card is not stimulating the motor development of children, especially gross motor skills. In fact, as previously mentioned, the development of motor skills are also important in the development of children.

Therefore, the researchers intend to design a toy that aims to help teachers introduce numbers and letters to children, while also helping to improve motoric ability of children, especially gross motor. This meant that the child's development is more balanced and is expected to become more optimal.

\section{THEORETICAL FRAMEWORK}

\subsection{Stages of Writing and Reading Development}

As children connections between spoken and written language, they extend their understanding to include symbolic forms that are used to capture speech. Here are the stages of writing development in children that developed by Temple (1992):

Stage 1: Scribble Stage. At this stage the child makes images that are not clearly visible.

Stage 2: Linear Repetitive Stage. Children's writing consist of horizontal stripes.

Stage 3: Random Letter Stage. At this stage, the child could write the letters, but they don't understand the meaning of those writing. The letters align and doesn't form a single word (but for the child, it is considered to be a word).

Stage 4: Letter-Name Writing / Phonetic Writing. Also called the sound system, which the child's writing are still the same as what they heard. For example: pasyen (patient)

Stage 5: Transitional Spelling. At this stage, children begin to recognize the standard system but sometimes they go back to the sound system.

Stage 6: Conventional Spelling. Children can write to the standard form properly.

On the other hand, Chall (1983) explain the stage of reading development as the following: Stage 0. Prereading: Birth to Age 6. The Pre-reading Stage covers a greater period of time and probably covers a greater series of changes than any of the other stages. From birth until the beginning of formal education, children living in a literate culture with an alphabetic writing system accumulate a fund of knowledge about letters, words, and books. The children grow in their control over various aspects of language-syntax and words. And they gain some insights into the nature of words: that some sound the same at their ends or beginnings (rhyme and alliteration), that they can be broken into parts, and that the parts can be put together (synthesized, blended) to form whole words.

Stage 1. Initial Reading, or Decoding, Stage: Grades 1-2, Ages 6-7. The essential aspect of Stage 1 is learning the arbitrary set of letters and associating these with the corresponding parts of spoken words. In this stage, children and adults interiorize cognitive knowledge about reading, such as what the letters are for, how to know that bun is not bug, and how to know when a mistake is made. The qualitative change that occurs at the end of this stage is the insight gained about the nature of the spelling system of the particular alphabetic language used.

Stage 2. Confirmation, Fluency, Ungluing from Print: Grades 2-3, Ages 7-8.6. Essentially, reading in Stage 2 consolidates what was learned in Stage 1. Reading stories previously heard increases fluency. Stage 2 reading is not for gaining new information, but for confirming what is already known to the reader.

Stage 3. Reading for Learning the New: A First Step. When readers enter Stage 3, they start on the long course of reading to "learn the new"-new knowledge, information, thoughts and experiences. Because their background (world) knowledge, vocabulary, and cognitive abilities are still limited at this stage, the first steps of Stage 3 reading are usually best developed with materials and purposes that are clear, within one viewpoint, and limited in technical complexities.

Stage 4. Multiple Viewpoints: High School, Ages 14-18. The essential characteristic of reading in Stage 4 is that it involves dealing with more than one point of view. Compared to the textbooks in the lower grades, the increased weight and length of high-school texts no doubt can be accounted for by greater depth of treatment and greater variety in points of view. Stage 
4 reading may essentially involve an ability to deal with layers of facts and concepts added on to those acquired earlier.

Stage 5. Construction and Reconstruction-A World View: College, Age 18 and Above. When Stage 5 is reached, one has learned to read certain books and articles in the degree of detail and completeness that one needs for one's purpose, starting at the end, the middle, or the beginning. A reader at Stage 5 knows what not to read, as well as what to read. To reach this stage is to be able to use selectively the printed material in those areas of knowledge central to one's concern.

From those stages, it can be concluded that the introduction to letters in young children must also consider the level of their development. This means that in introducing letters, teachers must concern at what level the child may show their reading acquisition.

\subsection{Motor Development in Early Childhood}

Motor development refers to changes in children's ability to control their body's movements, from infants' first spontaneous waving and kicking movements to the adaptive control of reaching, locomotion, and complex sport skills (Adolph, Weise, \& Marin, 2003). The term motor behavior describes all movements of the body, including movements of the eyes (as in the gaze), and the infant's developing control of the head. Gross motor actions include the movement of large limbs or the whole body, as in walking. Fine motor behaviors include the use of fingers to grasp and manipulate objects. Motor behaviors such as reaching, touching, and grasping are forms of exploratory activity (Adolph, Weise, \& Marin, 2003).

The period of the most rapid development of motor behaviors is in early childhood. In this moment, children make great advances both in gross-motor skills, such as running and jumping, which involve the large muscles, and fine motor skills, such as buttoning shirts and drawing pictures, which involve eye-hand and small muscle coordination (Papalia, Olds, \& Feldman, 2004).

Motor skills are an essential component of development for all children. Children need to move a lot. In early childhood, one of the importance of physical activities are helping reduce the increased health risks associated with obese and overweight children. Movement activities are also well-suited to helping children develop social skills. As children participate in group tasks that require movement, they learn that their efforts are critical to the success of the group. Simple games for young children also require cooperation and positive social skills. Another advantage of physical activity is that it has long been viewed as a positive way to release the pent-up energy generated from strong emotions. For example, vigorous physical activity such as running outdoors is generally considered an acceptable way to get rid of angry feelings. Such activities are far more positive than aggressive interactions with other children (Henniger, 2010).

Therefore, considering the importance of the development of gross-motor skills in early childhood, the toy is designed to stimulate motor skills, while at the same time, it also enhancing their ability to remember the letters.

\section{METHODOLOGY}

As mentioned before, the researchers intend to design a toy that aims to help teachers introduce numbers and letters to children, while also helping to improve motoric ability of children, especially gross motor. The design of the toy is explained at the following:

1. The first part of the toy is the Jumping Alphabet jump station. It made from laminated canvas, which printed with the design of the Jumping Alphabet, which is consist of a picture of 26 alphabet.

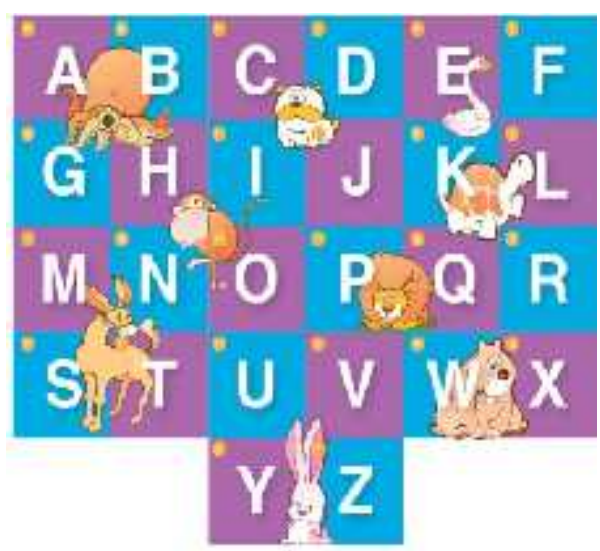

Figure 1. Jumping Alphabet Jump Station 
2. The second part of the toy is a flash-cards. In each card, it contains a picture of an object and the name of the object.

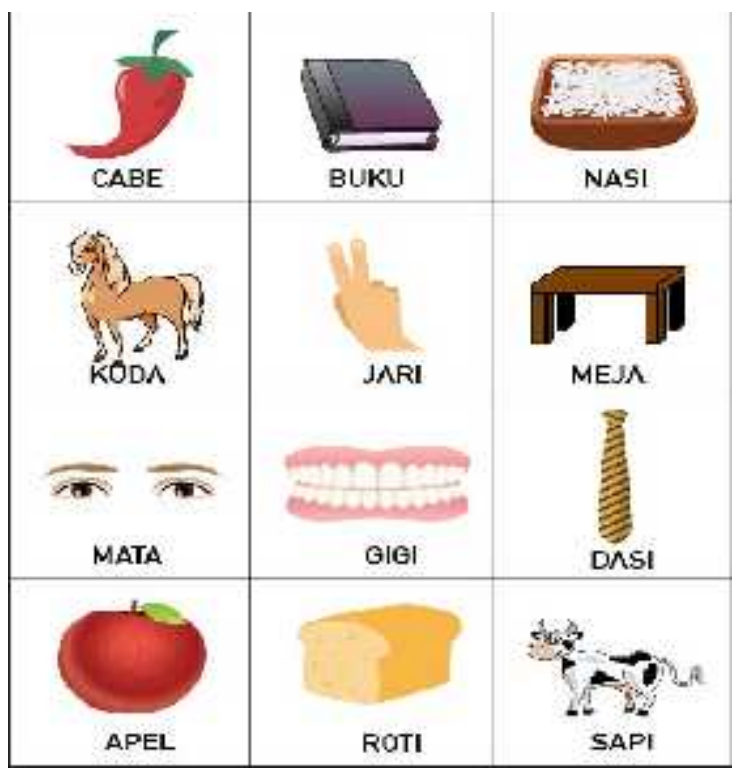

Figure 2. Design of The Flash-cards

Here is the explanation of how to use this Jumping Alphabet:

- Teachers put the jump station on the floor and give the cards to the children, each child get at least one card.
- $\quad$ Ask the child to show their card to their friends, and jump in a correspondence letters in the jump station that are the same with the letters in their card, and mention the letters loudly so their friend can hear.

- $\quad$ Give them applause if they succeed, and fix it if they made a mistake.

- $\quad$ Ask them to change cards among their friends or make a new card with different theme.

The first preliminary research of Jumping Alphabet was held in TK Bahagia, Malang, on the first week of December 2016. This trial followed by 10 children that is a student of TK Bahagia, as a sample of research. Based on observation to the children and also interview with the teacher before the trial was held, known that many of them have difficulties in recognizing letters and numbers. In this preliminary research, we used the observation sheet that will record the child's ability to recognize letters. First, as a pre-treatment, we observed their ability by showing them letters and ask them one by one to mention the letters. Many of them, as explained by their teacher, cannot mention the letters. After the data was collected, we ask the children to play the Jumping Alphabet for three days. And as a post treatment, we ask them once more about the letters that we showed them on the pre-treatment.

\section{RESULT AND CONCLUSIONS}

Based on the preliminary research that was held in TK Bahagia, the result is explained as the following:

Table 1. Result of Pre-treatment and Post-treatment

\begin{tabular}{|c|c|c|}
\hline No & Pre-treatment Observation & Post-treatment Observation \\
\hline 1. & $\begin{array}{l}6 \text { out of } 10 \text { children in the class } \\
\text { do not recognize many letters. }\end{array}$ & $\begin{array}{l}1 \text { out of } 10 \text { children in the class } \\
\text { still made a lot of mistakes in } \\
\text { recognizing the letters. }\end{array}$ \\
\hline 2. & $\begin{array}{l}9 \text { out of } 10 \text { children in the class } \\
\text { can't read a word consist of } 4 \\
\text { letters, such as 'mata' }\end{array}$ & $\begin{array}{l}5 \text { out of } 10 \text { children in the class } \\
\text { made more than } 3 \text { mistakes when } \\
\text { they were asked to read } 10 \text { words } \\
\text { consist of } 4 \text { letters that displayed in } \\
\text { flash-card. }\end{array}$ \\
\hline
\end{tabular}


Table 1. Cont

\begin{tabular}{l|l|l|l}
7 out of 10 children in the class & \multicolumn{2}{|c|}{ Only one children still have the } \\
had trouble in distinguishing the & $\begin{array}{l}\text { difficulties in distinguishing the } \\
\text { letters that have quite similar } \\
\text { shape, such as b-d, p-q. }\end{array}$ & letters.
\end{tabular}

Based on the table, it was concluded that there is a significant advancement and enhancement of the ability of students through the application of the media Jumping Alphabet in the classroom. For many children, playing is a fun activities that also help them to learn several concepts, including alphabet. It seemed to work on the toy Jumping Alphabet applied in this kindergarten. The children feel happy while playing, and they can release the tension they felt in the classroom, so they learn in good conditions that make the material of memorizing the letters can be absorbed optimally.

\section{ACKNOWLEDGEMENTS}

In this study, researchers focused only on one kindergarten. In the future, it is possible to reach more kindergartens and also playgroups so the toy can be evaluated more in depth and can provide better benefits to children who play it.

\section{REFERENCES}

Adolph, K. E., I. Weise, and L. Marin. 2003. "Motor Development" in Encyclopedia of Cognitive Science. London: Macmillan.

Chall, Jeanne S., 1983. Stages of Reading Development. New York: McGraw-Hill

Henniger, M.L. 2010. The Importance of Motor Skills. Date of access 09/12/2016 http://www.education.com/reference/article/im portance-motor-skills/

Papalia, Diane E., Olds, Sally W., Feldman, Ruth D. 2004. Human Development $9^{\text {th }}$ Ed. New York: McGraw-Hill.

Temple, C., 1992. The Beginnings of Writing: $3^{\text {rd }}$ Edition. Needham Heights, Mass: Allyn and Bacon. 